\title{
Analyzing the problem of falls among older people
}

This article was published in the following Dove Press journal:

International Journal of General Medicine

27 September 2012

Number of times this article has been viewed

\section{Yannis Dionyssiotis \\ Physical and Social Rehabilitation Center, Amyntaio, Florina, Greece}

Correspondence: Yannis Dionyssiotis Physical and Social Rehabilitation Center of Amyntaio, 2nd km National Road Amyntaio-Thessaloniki, 53200 Florina, Greece Tel +306946469759 (cell); +3023863503।2 (work) Email yannis_dionyssiotis@hotmail.com
Abstract: Falls are a serious problem facing the elderly. The prevention of falls that contribute to disability, mainly in elderly people, is an important issue. Ensuring the greatest possible functionality for elderly people is an important element in the prevention of disability. This paper analyzes the importance of falls, risk factors for falls, and interventions to prevent falls. Recent publications as well as research regarding the prevention and rehabilitation for falls are reviewed.

Keywords: falls, elderly, rehabilitation, risk factors

\section{The importance of falls}

A fall is an event which results in a person coming to rest inadvertently on the ground or other lower level, not as a consequence of the following: sustaining a violent blow, loss of consciousness, sudden onset of paralysis, or an epileptic seizure. ${ }^{1}$ Tinetti et al, in a pioneer paper published in 1988, defined a fall as an event which results in a person coming to rest unintentionally on the ground or other lower level, not as a result of a major intrinsic event (such as stroke) or overwhelming hazard. ${ }^{2}$ Falls are one of the most frequent and serious problems facing the elderly. Falls have a proven association with mortality, morbidity, reduced functionality, and premature nursing home admissions; are usually the result of interaction of multiple and diverse risk factors and situations that many times may be corrected; and their interaction is modified by age, disease, and the presence of hazards in the environment. ${ }^{3,4}$

In addition to falls occurring at high frequency in the elderly (children and athletes have an even higher incidence of falls), a key point is that the increased incidence of falls is combined with an increased susceptibility to injury. This propensity of the elderly to injuries results from the high incidence of accompanying diseases. For example, in osteoporosis, prevention and management should not only focus on bone strengthening but rather on subjects' muscle function and balance, which are directly linked to the disease. This can protect against falls, fractures, and the effects of aging (ie, slower reflexes), factors that can cause a relatively slight fall to be potentially dangerous. ${ }^{3,4}$

\section{Epidemiological data concerning falls}

More than $30 \%$ of people over 65 years of age fall each year and in half of the cases falls are recurrent. ${ }^{2}$ About one in ten falls results in serious injuries such as hip fracture, other fractures, subdural hematoma, or traumatic brain injury. ${ }^{5,6}$ Fifteen percent of falls are 
the result of a significant external event, which would cause a fall in most people. Falls of this type occur in younger, more active people. No special treatment is required. A similar number of falls is due to syncope episodes or neurological disorders (eg, epilepsy). The remaining $70 \%$ of falls result from the interaction of multiple risk factors. ${ }^{7,8}$ Regardless of general health status, falls are associated with less mobility, reduced capability to perform activities (eg, dressing, washing, and housework), and risk of admission to a nursing home..$^{9-11}$ Few falls are caused by a single risk factor; rather, the majority of falls are due to the association of so-called chronic and acute risk factors that one person may have in a particular environment. ${ }^{2-9}$ Moreover, the risk of falling increases as the risk factors increase. ${ }^{2}$ According to various studies, each of the following conditions have been proven to increase the risk of falling: arthritis, depression, cognitive incidents, vision and voiding problems, imbalance and gait deficits, reduced muscle strength, and also polypharmacy (more than four drugs)., ${ }^{2,12}$ Although there is a clear correlation between falls and taking a large number of drugs, some drugs are considered to be more dangerous in causing falls. Today, such drugs include serotonin blockers, tricyclic antidepressants, neuroleptic drugs, benzodiazepines, anticonvulsants, and some antiarrhythmic drugs. ${ }^{12}$

\section{Risk factors for falls in the elderly}

The individual risk factors for falls in the elderly are summarized below. ${ }^{13}$

\section{Intrinsic risk factors}

- History of falls: associated with an increased risk in recurrent falls.

- Age: falls increase with age because of a reduced ability to respond rapidly and effectively compared to younger adults. Moreover, studies of reaction time in old people observed a decrease in stepping, step initiation, and execution timing, ${ }^{14,15}$ and coordination time - which has also been linked to lower extremity fracture risk when breaking a fall by outstretching the hand is also delayed. ${ }^{16}$

- Gender: for the younger elderly, the rate of falls is similar for both men and women; however, among the most elderly people, women fall more often than men and are more likely to suffer from fractures when they fall.

- Solitary lifestyle: it may indicate greater functional capability, but injuries and their consequences could be even worse, especially if the person cannot get up from the floor. The fact that someone lives alone seems to be a risk factor in falls, although part of this effect appears to depend on the type of house in which they reside.

- Race: evidence from the United Kingdom and the United States suggests that Caucasian subjects fall more often than African tribes of the Caribbean, Hispanics, or South Asians, but there are no studies to report national differences in continental Europe.

- Drugs: the use of benzodiazepines in older people is associated with a $44 \%$ increase in risk of hip fracture and night falls. There is a significantly increased risk of falling when using drugs such as psychotropic, antiarrhythmic drugs, digoxin, diuretics, and sedatives. The degree of prescription of medicines has been increased in chronic disease management. According to almost all studies, the risk increases significantly if more than four medications are taken, regardless of the type of drug.

- Medical conditions: vascular diseases, chronic obstructive pulmonary disease, depression, and arthritis are each associated with a $32 \%$ increased risk. The frequency of falling increases with increasing deterioration due to chronic disease. Moreover, the risk increases with thyroid dysfunction, which leads to an excessive secretion of thyroid hormones, and also with diabetes and arthritis that leads to loss of peripheral sensation. The incidence of falls relevant to cardiovascular causes is unknown in the general population, but vertigo is common in people with falls. Depression and incontinence also occur frequently in populations with falls.

- Impaired mobility and gait: the reduction of strength and endurance after the age of 30 (10\% loss per decade) as well as muscle power (30\% loss per decade) lead to a decrease in physical function below the limit. As a result, daily living activities become difficult and then impossible - this is the case in early aging in generally sedentary subjects. When strength, endurance, power, and especially functionality are reduced considerably, it is not impossible for a false trip or a slip to turn into fall. Muscle weakness is a significant risk factor in falls, as well as difficulty in gait, imbalance, and the use of walking aids. Any disability of lower limbs (lack of power, orthopedic disorders, or poor sensation) is associated with increased risk. Having difficulty in getting up from a chair is also associated with increased risk.

- Deconditioning/immobility: those who fall tend to be less active and, through disuse, may cause further irreversible atrophy of the muscle around an unstable joint. Nonactive persons fall down more often than those who are moderately or very active, but fall down in a safe environment. 
- Psychological condition/fear of falling: up to $70 \%$ of people who have recently fallen down and up to $40 \%$ of those who have not reported a recent fall confess fears of falling. Reduced physical and functional activity is associated with stress and fear of falling. Up to $50 \%$ of those who fear falling limit or exclude social or physical activities because of this fear. Strong links were found between fear and poor posture, low-speed walking and muscle weakness, and poor health self-esteem and reduced quality of life. Women with a history of stroke are at greater risk of falling and experiencing fear of falling. Having four or more medications is also implicated in a fall-related phobia. However, many older people do not appreciate sufficiently the level of danger.

- Nutritional deficiencies: a low body mass index, which indicates poor nutrition, is associated with increased risk. Vitamin D deficiency is quite common in elderly people living in institutions and may lead to wrong gait patterns, muscle weakness, osteomalacia, and osteoporosis.

- Cognitive disorders: a lack of understanding is clearly associated with increased risk, even at relatively modest levels. For example, a result of less than 26 or less than 24 on the Mini Mental State Examination is related to increased risk. Poor memory has been proven to be an independent risk factor for falls in people over 75 years, according to LASA (Longitudinal Aging Study Amsterdam). Residents of institutions with dementia fall more than twice as often as people with normal cognition, but there is no difference in the severity of injury between the two groups.

- Attenuated vision: visual acuity, contrast sensitivity, field of vision, cataracts, glaucoma, and glaucoma plus bifocals or multifocal lenses lead to risk of falls. Multifocal lenses reduce the depth of perception and impair edge-contrast sensitivity when detecting obstacles in the environment. The elderly can benefit from wearing nonmultifocal glasses when using stairs and in unfamiliar surroundings outside their home.

- Foot problems: calluses on the big toe, long toe defects, ulcers, deformed nails, and general pain when walking increase the difficulty of balance and the risk of falls. Correctly fitting shoes are also important.

\section{Extrinsic risk factors}

The magnitude of the influence of environmental factors on the risk of falls in the elderly is uncertain. Some studies ${ }^{13}$ have indicated that in the elderly living in the community, 30\%-50\% of falls are due to environmental causes (eg, poor lighting, slippery floors, and uneven surfaces) and approximately $20 \%$ of falls are due to significant external factors (ie, those that would lead to a fall in any healthy elderly person). A frequent problem that older people encounter is to slip, trip, or misstep, ie, a loss of balance where righting mechanisms prevent a fall.

\section{Exposure to risk}

Some studies suggest a U-shaped association for exposure to risk, ${ }^{13}$ indicating that the more passive and more active people are at greater risk of falls. This shows the complexity of the relationship between falls, activity, and risk. The type and level of environmental challenges that an older person chooses to adopt interacts with the intrinsic risk factors of the individual. One study found that walking can increase the risk of falls, whereas others found that increased physical activity was associated with a reduced risk of falls but with an increased risk of serious injury. However, it actually seems to be beneficial for those who live in institutions to be engaged in medium- or high-level activities using a walking aid. Some activities seem to increase the risk of falls, either by increasing exposure to hazardous environmental conditions (slippery or uneven floors), acute fatigue, or by risky technique in performing exercises. ${ }^{7,17,18}$ Equally important to the identification of risk factors is the recognition of the interaction and potential synergies among multiple risk factors. The rate of falling increases from $27 \%$ for those with zero or one risk factor to $78 \%$ for those with four or more risk factors. ${ }^{2,19}$

\section{Assessment of risk of falls}

No screening tool able to assess the risk of falling among elderly people either in the community or in nursing homes has been used or certified all over Europe. However, the following tools have been used in a number of tests and clinical sites. ${ }^{20}$

- The STRATIFY (St Thomas Risk Assessment Tool in Falling Elderly Inpatients) risk assessment tool is simple to complete and identifies patients with a higher risk of falls. However, it is certified only for hospitalized patients. $^{21}$

- A screening tool based on the PROFET (Prevention of Falls in the Elderly Trial) study helps individuals monitored in a hospital's intensive care unit to recognize that they are in great danger. ${ }^{22}$

- A review of the literature was performed by Nandy et al to form a small group of questions that would identify people at high risk of falling who live in the community. FRAT (Falls Risk Assessment Tool) is a screening tool and 
reference for the community and it takes only 5 minutes to complete. It can be used by nonnursing staff, and has an accuracy of $97 \%$ (in the United Kingdom) in cases where someone has ticked four out of the five questions; however, it is not recommended for use in hospitals or nursing homes. ${ }^{23}$

- A screening test for risk of falling has been tested by Lips prospectively in 1285 residents of the community over 65 years, indicating that impaired vision, incontinence, previous falls, and the use of benzodiazepine were useful in determining falls or recurrent falls. However, this tool is of unknown sensitivity and precision. ${ }^{24}$ The same team constructed a risk profile for recurrent falls, which included five risk factors. In order of decreasing frequency, these factors were immobility, poor cognitive level, orthostatic hypotension, dizziness, and stroke. The participation of all risk factors in the profile implied an $84 \%$ probability of recurrent falls compared with $3 \%$ when there was no risk factors.

- The balance scale and the Tinetti scale of gait show an increased risk of falling if a person has more than six malfunctions in balance and gait. This scale has 24 items and therefore it is not practical to use in normal clinical practice. Moreover, it does not cover a wide range of risk factors and needs training from an expert to manage properly. The same applies to the Berg balance scale. Both scales have a "functional range" and "180 degree turn" in the functional testing within the framework of the scales. ${ }^{25}$

- Evaluation of the normal profile (Physiological Profile Assessment), developed by Lord et al, needs 45 minutes to operate and includes systems involved in maintaining a stable upright stance (gait, balance, vision, and proprioception - the vibration feeling and power); however, it fails to evaluate the medication, medical conditions, or household hazards. The functionality of each factor decreases with increasing age and possible disruptions or deficits in any one of them are accompanied by an increased risk of falling. Using this tool requires training and it is not practical for screening in routine clinical conditions. $^{26}$

- The guideline instructions of the American and British Geriatric Societies suggest the "Get Up and Go Test" as a simple screening test for persons with reduced strength and balance after the first fall. In the case of poor performance, a comprehensive evaluation should be performed. However, there are disadvantages. For example, the above test includes only basic movements of everyday living such as lifting, walking, turning, and seating but not stepping over a barrier which can cause a trip. ${ }^{13}$

- The Mobility Interaction Fall chart has been proven to be predictable when combined with a history of falling or subjective comments of the staff in nursing homes. This tool includes a comment on the ability to walk and interact with another person or object in parallel, a vision test, and level of concentration. ${ }^{27}$

- Researchers of the Laboratory for Research of Musculoskeletal System, University of Athens (Athens, Greece) presented a screening concept for high risk of falling based on the evaluation of subjects (mostly postmenopausal women) with jumping mechanography, clinical examinations of postural stability, and a questionnaire on falls. A Leonardo ${ }^{\mathrm{TM}}$ platform (Novotec Medical GmbH, Pforzheim, Germany) was used for the measurement of objective parameters of movement. The neuromuscular parameters of movement are the necessary variables for the diagnosis and treatment of the risk of falls. In the study of muscle capacity, movements should be described in terms that include the elements of strength, speed, and acceleration. Every movement is caused by the action of a force at a particular period of time and should therefore be measured as power. ${ }^{28}$ This methodology in a mixed population that included young adults and elderly had a reproducibility of about 0.99. ${ }^{29}$ In healthy women, a decrease of personal power (power/weight) from young to old was found. The value of the Hellenic Osteoporosis Foundation Fitness Index, which was based on previous publications by Runge from studies in the German population (Esslinger Fitness Index), was also calculated. A value of 100\% represents average healthy Greek women of the material tested in regarding to the power/weight parameter. Based on this personal power curve, women were evaluated for an increased risk of falling (ie, women with lower values than normal). ${ }^{30}$ A second diagnostic tool included heel to toe walking (tandem walking) with one hand on the wall or a solid surface (eg, handrail) and freely. This pattern of lateral gait is dependent on the torques of the adductors-abductors muscles in the hip joint and the adjustment of body movement. Previous published studies that assessed body balance control in the lateral plane of motion found that lateral stability was impaired and directly related to falls among the elderly. The effects of aging on balance are worsened in the mid-lateral direction; moreover, measurements of mid-lateral oscillation are associated with future risk of falls. ${ }^{31}$ Any subject 
with clinically evaluated instability during this test was assessed as at high risk of falling. The third tool was a questionnaire on falls with a score specifically designed for the Hellenic Osteoporosis Foundation (in Greek). ${ }^{32}$ The validated Greek version of the Falls Efficacy ScaleInternational Version for the documentation of fall-related self-efficacy in older persons was also included. ${ }^{33}$ This version was modified from the original Falls Efficacy Scale to include additional items on complex functional performances and social aspects of falls. This questionnaire was developed by a European Union-funded expert network (Prevention of Falls Network Europe) $)^{34}$ to focus and coordinate ongoing European clinical, research, and technology developments related to prevention of falls amongst elderly people. Prevention of Falls Network Europe is a thematic network focusing on the issue of prevention of falls and improvement of postural stability amongst elderly people. ${ }^{20,35}$

\section{Exercise and risk of falls}

The U-shaped relationship between activity and fall risk has already been mentioned, in which the most inactive and most active subjects are at the highest risk of experiencing a fall. ${ }^{13}$ Indeed, the results from MrOS (Osteoporotic Fractures in Men Study), a prospective cohort study enrolled 5995 community-dwelling men with 4.5 years of follow-up, observed an increased risk of falling with higher levels of self-reported physical activity; moreover, men with low leg power had consistent fall risk across all levels of physical activity, while men with high leg power had an increased fall risk with increasing physical activity levels. ${ }^{35}$

Several randomized controlled trials concluded that there was an inverse relationship between increased physical activity and risk of falls, and recommended low impact, balance, and coordination exercises. ${ }^{36-47} \mathrm{~A}$ metaanalysis of the several separate studies that made up the FICSIT (Frail and Injuries: Cooperative Studies of Intervention Techniques) trials found a $17 \%$ reduction of falls in individuals participating in endurance training, balance training, and tai chi, while tai chi showed a $47 \%$ reduction in multiple falls during a 4-month period compared to the controls. ${ }^{48,49}$ A Cochrane review including 111 studies $(55,303$ participants) concluded that multiple-component group exercise reduced the risk of falling by $17 \%$, as did tai chi and individually prescribed multiple-component home-based exercise (35\% and $23 \%$, respectively). ${ }^{50}$ However, the current evidence does not support home-based exercise intervention in people with severe visual impairment or mobility problems after a stroke, Parkinson's disease, or hip fracture. ${ }^{51-53}$

\section{Interventions to prevent falling in elderly subjects}

These interventions can be divided into either populationbased interventions or interventions aimed at specific groups at high risk of falling, such as women, delicate elderly, or people who have fallen in the past. ${ }^{54}$

Interventions to prevent falls may be planned to reduce a single internal or external risk factor of falling or be broadly focused to reduce multiple risk factors simultaneously. ${ }^{54,55}$ Single evidence-based interventions include exercise, reassessment of medications, and environmental modification. ${ }^{33,56}$

\section{Types of simple interventions: decreasing a single risk factor}

Physical activity and reduction of psychotropic drugs are highly effective in decreasing the total number of falls, injuries, and hospitalization due to falls.

\section{Intervention with exercise}

Tai chi is a promising type of balance exercise, although it requires further evaluation before it can be recommended as the preferred method for balance training. Tai chi consists of slow, rhythmic movements emphasizing trunk rotation, weight shifting, coordination, and a gradual narrowing of lower extremity stance, and is thought to be an excellent choice of exercise for the elderly. There is experimental evidence from both cross-sectional and longitudinal studies that tai chi exercise has beneficial effects on balance control and that the postural stability is improved more by tai chi than by other types of exercise. ${ }^{57-60}$ Twenty congregate living facilities in the United States took part in a 48-week randomized control trial of tai chi in 311 transitionally frail men and women (mean age 80.9 years; range 70-97 years) with at least one fall in the prior year. The intervention was an intense tai chi exercise program while controls received a wellness education program for the same period of time. The fallers (one or more falls) had a $47.6 \%$ fall rate with intervention tai chi versus a fall rate of $60.3 \%$ in controls, a nonsignificant difference. ${ }^{61}$ Tai chi is probably the exercise program least recommended to people who have previously suffered fractures because they show a level of frailty, which means they could not fully participate in tai chi unless it was adapted so much that it was no longer dynamic balance training 
(Skelton D, personal communication, September 2006). Low intensity balance exercises (walking heal to toe and standing on one foot) along with coordination exercises are proposed for falls prevention. People with reduced bone strength can benefit from hydrotherapy in therapeutic pools or swimming in the sea. It is suggested to these people to perform strengthening exercises of the quadriceps, abductors, adductors, and shoulder muscles. ${ }^{46}$ According to the Greek guidelines of the Hellenic Osteoporosis Foundation, although exercise has many proven benefits, the optimal type, duration, and intensity of exercise for falls prevention remains unclear. Older people who have had recurrent falls should be offered long-term exercise and balance training. ${ }^{20,35}$

Chang et al in a review about the effectiveness of interventions to prevent falls in older adults concluded that exercise programs help prevent falls with no differences between types of exercise. ${ }^{62}$ The results from the FICSIT trials suggest that interventions that addressed strength alone did not reduce falls. On the other hand, balance training may be more effective in lowering falls risk than the other exercise components. ${ }^{47}$ Gardner et al concluded that exercise programs must be regular and sustainable to be effective, but more trials are required to determine the exercise type, frequency, duration, and intensity that are most effective in lowering fall risk in different groups of older people. ${ }^{63}$ However, as aging is related to reduced physical functioning (frailty), exercise prescription for falls prevention, except balance and strength training, may include exercises to increase the functional capabilities in all elderly. The suggested solutions, especially for the Greek population, are low intensity balance exercises (tandem walking and standing on one foot) combined with coordination exercises. Individuals who are frail, severely kyphotic, or suffer from pain or poor balance may benefit from water exercise (hydrotherapy). People are also advised to undergo strengthening exercises of the quadriceps, hip abductors/extensors, back extensors, and the arm muscles. ${ }^{20,46}$

\section{The effect of drugs}

In patients with recurrent falls, the pharmaceutical treatment needs to be reviewed, modified, or discontinued as appropriate to reduce the risk of a future fall. Particular attention should be given to decreasing the medication of older people who receive four or more medications and to those taking psychotropic medications. ${ }^{64-66}$ All medicines, including overthe-counter drugs, should be reviewed in detail regarding their continuation or discontinuation. The aim should be to maximize the overall health and functional benefits of the patient while reducing negative consequences such as falls. Psychotropic drugs require special attention, since there are strong indications that their use is associated with a future fall. Reducing the total number of drugs to four or less, if possible, has also been proven to reduce the risk of falling. ${ }^{1,25}$ The changes in body composition in elderly subjects (primarily due to reduction of total water) require attention to the dose of water-soluble medicines, eg, nitrates, aminoglycosides, antihypertensives. Due to the possible decrease of renal and hepatic function, the dose of aminoglycosides, nonsteroidal antiinflammatory drugs, cimetidine, propranolol, nitrides, and morphine should be modified. Finally, hypoalbuminemia requires special handling in cases where drugs such as quinidine, rifampicin, and propranolol are being used. ${ }^{67}$

\section{Calcium and vitamin D}

There is emerging clinical evidence that alfacalcidol, a prodrug of D-hormone, improves muscle function. ${ }^{28,68}$ Dukas et al showed that $1 \mu \mathrm{g}$ alfacalcidol daily significantly reduces the number of falls $(-54 \%)$ and fallers $(-55 \%)$ in community-dwelling elderly women and men with a total calcium intake of more than $500 \mathrm{mg}$ daily and normal vitamin D serum levels. ${ }^{69}$ Other authors reported that cholecalciferol-calcium supplementation reduces falls by $46 \%$ to $65 \%$ in community-dwelling older women, but has a neutral effect on falls in men. ${ }^{70}$

Flicker et al performed a 2-year, multicenter, randomized controlled trial in 625 participants with serum 25-hydroxyvitamin D levels between 25-90 nmol/L who were given ergocalciferol (vitamin D) (initially 10,000 IU once weekly, then $1000 \mathrm{IU}$ daily) combined with $600 \mathrm{mg}$ calcium carbonate per day. Vitamin D supplementation was associated with an incident rate ratio for falling of 0.73 and odds ratio for ever falling of 0.82 , while subjects who reported half compliance demonstrated values of 0.63 and 0.70 , respectively. ${ }^{71}$

The study of Broe et al was a 5-month, randomized, multiple-dose study in which one of four doses of vitamin D (200 IU, 400 IU, 600 IU, or 800 IU) or placebo was administered to 124 long-term nursing home residents. It was found that the proportion of fallers in the placebo group was $44 \%, 58 \%$ in the 200 IU group, $60 \%$ in the 400 IU group, $60 \%$ in the 600 IU group, and $20 \%$ in the $800 \mathrm{IU}$ group, while residents in the highest-dose group had a $72 \%$ lower adjusted-incidence rate ratio of falls than participants receiving placebo. ${ }^{72}$ 


\section{Types of simple interventions: multifactorial interventions}

An individualized rehabilitation program for falls and fall-related fracture prevention

Prevention of falls may be even more effective when taking into account multiple risk factors for falling. Most multifactorial fall prevention programs have been successful in reducing the incidence of falls and the risk factors of falls, particularly when prevention is individually tailored for their needs and targeted to populations at high risk for falls. These results suggest that an individualized prevention program aimed at reducing multiple risk factors simultaneously in high-risk populations could be an effective strategy for preventing falls; however, the exact content of the most effective approaches remains unclear. ${ }^{73}$

The dual role of rehabilitation includes prevention and avoidance of falls and fall-related fractures. Falls are a serious problem facing the elderly. Falling results in increased mortality, morbidity, reduced functioning, and premature nursing home admissions. Falls generally result from an interaction of multiple and diverse risk factors and situations, many of which can be corrected. ${ }^{34}$

Falls can also result in deterioration of physical functioning and quality of life due to injury or fear of falling. Nevitt et al found that $16 \%$ of fallers reported that they limited their usual activity because of fear of falling and one-third of fallers reduced their participation in social activities. According to Yardley et al, fear of falling is reported by one in four older people in the community and can lead to distress and reduced quality of life, increased medication use and activity restriction, further decline in physical functioning, greater falling risk, and admission to institutional care. ${ }^{74}$

It is necessary to assess possible intrinsic and extrinsic risk factors for falls, as well as exposure to individual risk. ${ }^{14}$ Identifying risk factors is as important as appreciating the interaction and probable synergism between multiple risk factors because, as mentioned previously, the rate of falling increases from $27 \%$ for those with zero or one risk factor to $78 \%$ for those with four or more risk factors. ${ }^{2}$

Important potentially modifiable risk factors for community-dwelling older adults are: mental status and psychotropic drugs, multiple drugs, environmental hazards, vision, lower extremity impairments, balance, and gait status. Important potentially modifiable risk factors for institution-dwelling older adults are: mental status, depression, urinary incontinence, hypotension, hearing, balance, gait, lower extremity impairments, low activity level (exercise less than once a week), psychotropic drugs, cardiac drugs, analgesics, and use of a mechanical restraint. Nonmodifiable risk factors (eg, hemiplegia, blindness) also exist. ${ }^{56}$

\section{Environmental modifications}

Environmental hazards can be a cause of falls. ${ }^{22}$ In reducing environmental hazards, fall prevention programs may need to provide and install safety devices particularly in people's homes. ${ }^{41}$ Studies have shown that when older patients at increased risk of falls are discharged from the hospital, a facilitated environmental home assessment should be considered. ${ }^{54,55}$

\section{Mobility aids and educational programs}

Studies of multifactorial interventions, which included both devices (including alarms in bed, canes, walkers, and hip protection $)^{75,76}$ and educational programs, have demonstrated benefit. ${ }^{77-79}$ However, there is no direct evidence that only the use of aid devices or educational programs can help the prevention of falls. Therefore, although they may be effective elements of a multifactorial intervention program, their isolated use without attention to other risk factors cannot be established.

\section{Conclusion}

The author supports a multidisciplinary rehabilitation approach that emphasizes both functional recovery and restoration of quality of life. Degenerative changes accompanying the aging process and environmental factors should be kept in mind. From this point of view, the solution to the problem of falls cannot be handled with pharmacological treatment only. Elderly subjects should be informed about the benefits of exercise and home safety. Moreover, it is a necessity to inform public authorities about the issue of falls.

\section{Disclosure}

The author reports no conflicts of interest in this work.

\section{References}

1. Kellogg International Working Group on the Prevention of Falls by the Elderley. The prevention of falls in later life. Dan Med Bull. 1987;34(Suppl 4):1-24.

2. Tinetti ME, Speechley M, Ginter SF. Risk factors for falls among elderly persons living in the community. N Engl J Med. 1988;319(26): 1701-1707.

3. Rubenstein LZ, Josephson KR. The epidemiology of falls and syncope. Clin Geriatr Med. 2002;18(2):141-158.

4. Nevitt MC, Cummings SR, Kidd S, Black D. Risk factors for recurrent nonsyncopal falls. A prospective study. JAMA. 1989;261(18):2663-2668. 
5. Nevitt MC, Cummings SR, Hudes ES. Risk factors for injurious falls: a prospective study. J Gerontol. 1991;46(5):M164-M170.

6. Sattin RW. Falls among older persons: a public health perspective. Annu Rev Public Health. 1992;13:489-508.

7. Rubenstein LZ, Powers CM, MacLean CH. Quality indicators for the management and prevention of falls and mobility problems in vulnerable elders. Ann Intern Med. 2001;135(8 Pt 2):686-693.

8. Campbell AJ, Robertson MC. Implementation of multifactorial interventions for fall and fracture prevention. Age Ageing. 2006;35(Suppl 2):ii60-ii64

9. Tinetti ME, Doucette J, Claus E, Marottoli R. Risk factors for serious injury during falls by older persons in the community. J Am Geriatr Soc. 1995;43(11):1214-1221.

10. Tinetti ME, Williams CS. The effect of falls and fall injuries on functioning in community-dwelling older persons. J Gerontol A Biol Sci Med Sci. 1998;53(2):M112-M119.

11. Tinetti ME, Williams CS. Falls, injuries due to falls, and the risk of admission to a nursing home. $N$ Engl J Med. 1997;337(18):1279-1284.

12. Leipzig RM, Cumming RG, Tinetti ME. Drugs and falls in older people: a systematic review and meta-analysis: I. Psychotropic drugs. $J$ Am Geriatr Soc. 1999;47(1):30-39.

13. Todd C, Skelton D; Health Evidence Network. What are the Main Risk Factors for Falls Among Older People and What are the Most Effective Interventions to Prevent These Falls? Geneva: World Health Organiztion; 2004.

14. Maki BE, McIlroy WE. Control of compensatory stepping reactions: age-related impairment and the potential for remedial intervention. Physiother Theory Pract. 1999;15(2):69-90.

15. Rogers MW, Kukulka CG, Brunt D, Cain TD, Hanke TA. The influence of stimulus cue on the initiation of stepping in young and older adults. Arch Phys Med Rehabil. 2001;82(5):619-624.

16. Adelsberg S, Pitman M, Alexander H. Lower extremity fractures: relationship to reaction time and coordination time. Arch Phys Med Rehabil. 1989;70(10):737-739.

17. Graafmans WC, Ooms ME, Hofstee HM, Bezemer PD, Bouter LM, Lips P. Falls in the elderly: a prospective study of risk factors and risk profiles. Am J Epidemiol. 1996;143(11):1129-1136.

18. O'Loughlin JL, Robitaille Y, Boivin JF, Suissa S. Incidence of and risk factors for falls and injurious falls among the community-dwelling elderly. Am J Epidemiol. 1993;137(3):342-354.

19. Rubenstein LZ, Josephson KR. Falls and their prevention in elderly people: what does the evidence show? Med Clin North Am. 2006; 90(5):807-824.

20. Dionyssiotis Y. Hellenic Osteoporosis Foundation. [Exercise for Osteoporosis and Falls Prevention]. Athens: Hellenic Osteoporosis Foundation; Greek; 2008.

21. Oliver D, Papaioannou A, Giangregorio L, Thabane L, Reizgys K, Foster G. A systematic review and meta-analysis of studies using the STRATIFY tool for prediction of falls in hospital patients: how well does it work? Age Ageing. 2008;37(6):621-627.

22. Close J, Ellis M, Hooper R, Glucksman E, Jackson S, Swift C. Prevention of Falls in the Elderly Trial (PROFET): a randomised controlled trial. Lancet. 1999;353(9147):93-97.

23. Nandy S, Parsons S, Cryer C, et al. Development and preliminary examination of the predictive validity of the Falls Risk Assessment Tool (FRAT) for use in primary care. J Public Health (Oxf). 2004;26(2):138-143.

24. Lips P. Epidemiology and predictors of fractures associated with osteoporosis. Am J Med. 1997;103(2A):3S-8S.

25. Tinetti ME. Clinical practice. Preventing falls in elderly persons. N Engl J Med. 2003;348(1):42-49.

26. Lord SR, Menz HB, Tiedemann A. A physiological profile approach to falls risk assessment and prevention. Phys Ther. 2003;83(3):237-252.

27. Lundin-Olsson L, Nyberg L, Gustafson Y. The Mobility Interaction Fall chart. Physiother Res Int. 2000;5(3):190-201.

28. Runge M, Schacht E. Multifactorial pathogenesis of falls as a basis for multifactorial interventions. $J$ Musculoskelet Neuronal Interact. 2005;5(2):127-134.
29. Rittweger J, Schiessl H, Felsenberg D, Runge M. Reproducibility of the jumping mechanography as a test of mechanical power output in physically competent adult and elderly subjects. $J$ Am Geriatr Soc. 2004;52(1):128-131.

30. Dionyssiotis Y, Galanos A, Michas G, Trovas G, Lyritis GP. Assessment of musculoskeletal system in women with jumping mechanography. Int $J$ Womens Health. 2010;1:113-118.

31. Lord SR, Rogers MW, Howland A, Fitzpatrick R. Lateral stability, sensorimotor function and falls in older people. J Am Geriatric Soc. 1999;47(9):1077-1081.

32. Dionyssiotis Y. Falls in the elderly. Galenus. 2010;52(4):317-336.

33. Billis E, Strimpakos N, Kapreli E, et al. Cross-cultural validation of the Falls Efficacy Scale International (FES-I) in Greek community-dwelling older adults. Disabil Rehabil. 2011;33(19-20):1776-1784.

34. Skelton DA, Becker C, Lamb SE, et al. Prevention of Falls Network Europe: a thematic network aimed at introducing good practice in effective falls prevention across Europe. Eur J Aging. 2004;1(1):89-94.

35. Hellenic Osteoporosis Foundation. Guidelines for the Diagnosis and Treatment of Osteoporosis in Greece. Athens: Hellenic Osteoporosis Foundation; 2009.

36. Karlsson MK, Nordqvist A, Karlsson C. Physical activity, muscle function, falls and fractures. Food Nutr Res. 2008;52. doi: 10.3402/ fnr.v52i0.1920.

37. Greenspan SL, Myers ER, Maitland LA, Resnick NM, Hayes WC. Fall severity and bone mineral density as risk factors for hip fracture in ambulatory elderly. JAMA. 1994;271(2):128-133.

38. Lord SR, Ward JA, Williams P, Strudwick M. The effect of a 12-month exercise trial on balance, strength, and falls in older women: a randomized controlled trial. J Am Geriatr Soc. 1995;43(11):1198-1206.

39. McMurdo ME, Mole PA, Paterson CR. Controlled trial of weight bearing exercise in older women in relation to bone density and falls. $B M J$. 1997;314(7080):569.

40. Buchner DM, Cress ME, de Lateur BJ, et al. The effect of strength and endurance training on gait, balance, fall risk, and health services use in community-living older adults. J Gerontol A Biol Sci Med Sci. 1997;52(4):M218-M224.

41. Tinetti ME, Baker DI, McAvay G, et al. A multifactorial intervention to reduce the risk of falling among elderly people living in the community. N Engl J Med. 1994;331(13):821-827.

42. Campbell AJ, Robertson MC, Gardner MM, Norton RN, Tilyard MW, Buchner DM. Randomised controlled trial of a general practice programme of home based exercise to prevent falls in elderly women. BMJ. 1997;315(7115):1065-1069.

43. Campbell AJ, Robertson MC, Gardner MM, Norton RN, Buchner DM. Falls prevention over 2 years: a randomized controlled trial in women 80 years and older. Age Ageing. 1999;28(6):513-518.

44. Campbell AJ, Robertson MC, Gardner MM, Norton RN, Buchner DM. Psychotropic medication withdrawal and a home-based exercise program to prevent falls: a randomized, controlled trial. $J$ Am Geriatr Soc. 1999;47(7):850-853.

45. Rubenstein LZ, Josephson KR, Trueblood PR, et al. Effects of a group exercise program on strength, mobility, and falls among fall-prone elderly men. J Gerontol A Biol Sci Med Sci. 2000;55(6):M317-M321.

46. Dionyssiotis Y, Dontas IA, Economopoulos D, Lyritis GP. Rehabilitation after falls and fractures. J Musculoskelet Neuronal Interact. 2008;8(3):244-250.

47. Lord SR, Sherrington C, Menz HB, Close J. Falls in Older People: Risk Factors and Strategies for Prevention. 2nd ed. New York, NY: Cambridge University Press; 2007.

48. Province MA, Hadley EC, Hornbrook MC, et al. The effects of exercise on falls in elderly patients. A preplanned meta-analysis of the FICSIT Trials. JAMA. 1995;273(17):1341-1347.

49. Ory MG, Schechtman KB, Miller JP, et al. Frailty and injuries in later life: the FICSIT trials. JAm Geriatr Soc. 1993;41(3):283-296.

50. Gillespie LD, Robertson MC, Gillespie WJ, et al. Interventions for preventing falls in older people living in the community. Cochrane Database Syst Rev. 2009;2:CD007146. 
51. Wolf SL, Barnhart HX, Ellison GL, Coogler CE. The effect of tai chi quan and computerized balance training on postural stability in older subjects. Phys Ther. 1997;77(4):371-381.

52. Wolf SL, Barnhart HX, Kutner NG, McNeely E, Coogler C, Xu T. Reducing frailty and falls in older persons: an investigation of tai chi and computerized balance training. J Am Geriatr Soc. 1996;44(5): 489-497.

53. Verhagen AP, Immink M, van der Meulen A, Bierma-Zeinstra SM. The efficacy of tai chi chuan in older adults: a systematic review. Fam Pract. 2004;21(1):107-113.

54. Cumming RG, Thomas M, Szonyi G, et al. Home visits by an occupational therapist for assessment and modification of environmental hazards: a randomized trial of falls prevention. J Am Geriatr Soc. 1999;47(12):1397-1402.

55. Sattin RW, Rodriguez JG, DeVito CA, Wingo PA. Home environmental hazards and the risk of fall injury events among community-dwelling older persons. J Am Geriatr Soc. 1998;46(6):669-676.

56. Moreland J, Richardson J, Chan DH, et al. Evidence-based guidelines for the secondary prevention of falls in older adults. Gerontology. 2003;49(2):93-116.

57. Mark BS. Combined Tai Chi Chuan. Boston, MA: Chinese Wushu Research Institute; 1979.

58. Wolf SL, Coogler C, Xu T. Exploring the basis for tai chi chuan as a therapeutic exercise approach. Arch Phys Med Rehabil. 1997;78(8): 886-892.

59. Wolfson L, Whipple R, Derby C, et al. Balance and strength training in older adults: intervention gains and tai chi maintenance. J Am Geriatr Soc. 1996;44(5):498-506.

60. Tse SK, Bailey DM. Tai chi and postural control in the well elderly. Am J Occup Ther. 1992;46(4):295-300.

61. Wolf SL, Sattin RW, Kutner M, O’Grady M, Greenspan AI, Gregor RJ. Intense tai chi exercise training and fall occurrences in older, transitionally frail adults: a randomized, controlled trial. J Am Geriatr Soc. 2003;51(12):1693-1701.

62. Chang JT, Morton SC, Rubenstein LZ, et al. Interventions for the prevention of falls in older adults: systematic review and metaanalysis of randomised clinical trials. BMJ. 2004;328(7441): 680-687.

63. Gardner MM, Robertson MC, Campbell AJ. Exercise in preventing falls and fall related injuries in older people: a review of randomised controlled trials. Br J Sports Med. 2000;34(1):7-17.

64. Woolcott JC, Richardson KJ, Wiens MO, et al. Meta-analysis of the impact of 9 medication classes on falls in elderly persons. Arch Intern Med. 2009;169(21):1952-1960.

65. Ensrud KE, Blackwell TL, Mangione CM, et al. Central nervous systemactive medications and risk for falls in older women. J Am Geriatr Soc. 2002;50(10):1629-1637.
66. Weiner DK, Hanlon JT, Studenski SA. Effects of central nervous system polypharmacy on falls liability in community-dwelling elderly. Gerontology. 1998;44(4):217-221.

67. Argyriadou S, Charisi A, Melissopoulou C, et al. Gait disorders in elderly people and investigation of their correlation with the most common neuropsychiatric disorders. Primary Health Care. 1999;11(2): 77-84.

68. Bischoff-Ferrari HA, Orav EJ, Dawson-Hughes B. Effect of cholecalciferol plus calcium on falling in ambulatory older men and women: a 3-year randomized controlled trial. Arch Intern Med. 2006;166(4): 424-430.

69. Dukas L, Bischoff HA, Lindpaintner LS, et al. Alfacalcidol reduces the number of fallers in a community-dwelling elderly population with a minimum calcium intake of more than $500 \mathrm{mg}$ daily. J Am Geriatr Soc. 2004;52(2):230-236.

70. Bischoff-Ferrari HA, Dawson-Hughes B, Willett WC, et al. Effect of vitamin D on falls: a meta-analysis. JAMA. 2004;291(16): 1999-2006.

71. Flicker L, MacInnis RJ, Stein MS, et al. Should older people in residential care receive vitamin $\mathrm{D}$ to prevent falls? Results of a randomized trial. J Am Geriatr Soc. 2005;53(11):1881-1888.

72. Broe KE, Chen TC, Weinberg J, Bischoff-Ferrari HA, Holick MF, Kiel DP. A higher dose of vitamin D reduces the risk of falls in nursing home residents: a randomized, multiple-dose study. J Am Geriatr Soc. 2007;55(2):234-239.

73. Sjosten NM, Salonoja M, Piirtola M, et al. A multifactorial fall prevention programme in home-dwelling elderly people: a randomizedcontrolled trial. Public Health. 2007;121(4):308-318.

74. Yardley L, Beyer N, Hauer K, Kempen G, Piot-Ziegler C, Todd C. Development and initial validation of the Falls Efficacy ScaleInternational (FES-I). Age Ageing. 2005;34(6):614-619.

75. Dean E, Ross J. Relationships among cane fitting, function, and falls. Phys Ther. 1993;73(8):494-500.

76. Tideiksaar R, Feiner CF, Maby J. Falls prevention: the efficacy of a bed alarm system in an acute-care setting. Mt Sinai J Med. 1993;60(6): $522-527$.

77. Tennstedt S, Howland J, Lachman M, et al. A randomized, controlled trial of a group intervention to reduce fear of falling and associated activity restriction in older adults. J Gerontol B Psychol Sci Soc Sci. 1998;53(6):P384-P392.

78. Baraff LJ, Lee TJ, Kader S, Della Penna R. Effect of a practice guideline on the process of emergency department care of falls in elder patients. Acad Emerg Med. 1999;6(12):1216-1223.

79. Baraff LJ, Lee TJ, Kader S, Della Penna R. Effect of a practice guideline for emergency department care of falls in elder patients on subsequent falls and hospitalizations for injuries. Acad Emerg Med. 1999;6(12):1224-1231.
International Journal of General Medicine

\section{Publish your work in this journal}

The International Journal of General Medicine is an international, peer-reviewed open-access journal that focuses on general and internal medicine, pathogenesis, epidemiology, diagnosis, monitoring and treatment protocols. The journal is characterized by the rapid reporting of reviews, original research and clinical studies across all disease areas.

\section{Dovepress}

A key focus is the elucidation of disease processes and management protocols resulting in improved outcomes for the patient. The manuscript management system is completely online and includes a very quick and fair peer-review system. Visit http://www.dovepress.com/ testimonials.php to read real quotes from published authors. 